\title{
BIBLIOTECA DE HIPERTEXTOS PARA ANÁLISE ORGANIZACIONAL: \\ O Sistema Panteon como Plataforma Aberta de Desenvolvimento Colaborativo de Estudos de Casos Online
}

\author{
1- Gustavo da Silva Motta \\ Universidade Federal da Bahia - UFBA \\ gustavosmotta@gmail.com
}

\author{
2- Marcos Cerqueira Lima \\ Universidade Federal da Bahia - UFBA \\ limamarcos@gmail.com
}

\section{RESUMO}

Este artigo discute a possibilidade de desenvolvimento de uma rede de colaboração no intuito de consolidar uma ferramenta web, de livre uso, com o potencial de adicionar elementos inovadores ao processo de ensinoaprendizagem em gestão. A necessidade de adequação desse processo às características sócio-culturais e tecnológicas hodiernas sugere a adoção mais ampla de ferramentas informáticas de apoio cognitivo aos estudantes de gestão em processos de análise organizacional qualitativa. Como forma de ilustrar algumas possibilidades futuras, são brevemente apresentadas experiências recentes de utilização de uma ferramenta colaborativa análise de casos hipertextuais. Nas três categorias de utilização experimentadas (análise de casos cadastrados no sistema; desenvolvimento de novos casos para subseqüente análise colaborativa; e, uso de casos hipertextuais para análise qualitativa em dinâmicas de jogos de empresa), observou-se a capacidade da ferramenta em dar suporte ao trabalho em equipe para a tomada de decisões, ao desenvolvimento de competências informacionais e ainda à capacidade de tratar a complexidade que envolve os domínios de conhecimento pouco estruturados. Conclui-se que o uso bem sucedido da ferramenta nestes três contextos pode servir de exemplo para a criação de uma biblioteca nacional de hipertextos para análise organizacional.

\begin{abstract}
This paper aims at discussing the possibility of establishing a collaborative network based on a freeware web-based tool with the potential to add innovative elements to the process of management teaching and learning. The current social, cultural and technological contexts require the widespread adoption of similar cognitive support tools for organizational analysis by business students. In order to illustrate some future possibilities, we briefly present recent experiences with the use of a hypertextual tool for collaborative case analysis. In all three of the experience scenarios (analysis of cases previously registered in the system; development and analysis of a new hypertextual case study and the use of the collaborative interface for qualitative analysis in a business game), we could observe how the tool contributed to the development of abilities of teamwork and decision making, besides the competency of information gathering and processing and also the capacity to deal with the complexity of illstructured knowledge domains. We concluded that the successful use of such web-based tool in these three contexts is a supporting evidence that it is possible to envisage the creation of a nation-wide library of hypertextual cases for organizational analysis.
\end{abstract}

Keywords

Panteon System. Case Method. Business Games. Hypertextual Cases. 


\section{Introdução}

Em vista das mudanças sócio-culturais e tecnológicas dos últimos dez anos, evidencia-se a preocupação de professores e pesquisadores da área de gestão em relação aos processos de ensino-aprendizagem contemporâneos, a exemplo do PCDA (Programa de Capacitação Docente em Administração) da ANPAD (Associação Nacional de Pós-graduação e Pesquisa em Administração). A ubiqüidade dos computadores nas Universidades e Faculdades de Administração do Brasil contrasta com o tradicionalismo dos processos de ensinar e aprender. $\mathrm{Na}$ grande maioria dos casos o uso da tecnologia está fundado na simples apresentação áudio-visual.

Os poucos casos de integração das novas tecnologias de informação e comunicação ao ensino têm permitido há algum tempo, especificamente ao curso de administração, a introdução de algumas técnicas como a simulação através de jogos de empresas (GOLDSCHMIDT, 1977; VICENTE, 2001; ROSAS e SAUAIA, 2006) e o desenvolvimento de sistemas de educação eletrônicos, que utilizam banco de dados (LIMA, 2003a; 2003b; 2001) auxiliando estudos de casos hipertextuais, a exemplo da ferramenta Panteon, objeto deste artigo.

Goldschmidt (1977) considera três desafios relacionados ao ensino de administração. O primeiro deles é a tomada de decisões. O que se observa é a falta de formalização e de ensino das etapas do processo decisório, considerando-as como componentes de uma estrutura ordenada, regular e metódica. Paradoxalmente, a tomada de decisões é considerada o encargo mais característico do administrador (JONES, 1973). Goldschmidt (1977) apresenta o segundo desafio afirmando que "do ponto de vista da empresa, que é um grupo, essas pessoas devem gerar uma única decisão, ou um único conjunto de decisões, não podendo prescindir de um acordo interno entre os membros do grupo" (GOLDSCHMIDT, 1977, p. 44). Evidencia-se assim, o estímulo ao trabalho em grupo e, desta forma, a necessidade da habilidade para lidar com pessoas. O terceiro desafio, para o autor, talvez seja o maior: conseguir abordar toda a complexidade do curso, dadas as muitas relações existentes entre as diversas disciplinas. Essas, devido à própria divisão do curso em frações curriculares isoladas, não são capazes de dar conta de tais relações.

Adicionalmente, é necessário se pensar num quarto desafio associado à evolução das redes telemáticas e emergência da chamada sociedade do conhecimento. Lima (2003a) demonstra a necessidade de utilização de abordagens de ensino mais condizentes com o atual ambiente sócio cultural dos gestores e as conseqüentes demandas à profissão. Para o autor, nesta sociedade do conhecimento, os futuros profissionais de gestão precisam estar capacitados a elaborar soluções a partir de ferramentas de informação; é necessário desenvolver a competência informacional, ou seja, a "capacidade de utilizar uma gama de ferramentas de informação como fonte primária de elaboração de soluções" (ISAAC, 2001, 144). Lima (2003a) afirma ainda que tais ferramentas difundem-se rapidamente pelo mundo corporativo, apesar de ser rara sua adoção nas escolas de gestão, e que esta capacitação envolve o estabelecimento de uma visão complexa e interdisciplinar, possíveis de serem desenvolvidas através de princípios construtivistas de aprendizagem. Desta forma, ao reconhecer a importância do chamado "Método Harvard" de estudos de caso para o ensino de gestão, Lima (2003a) propõe o Sistema Panteon como uma oportunidade de incremento à metodologia. É neste sentido que o presente trabalho tem como objetivo propor a adoção de tal ferramenta no ensino de gestão, criando, adicionalmente, um acervo de casos que possa ser compartilhado nacionalmente entre professores e pesquisadores.

A contextualização dessa proposta no presente artigo se dará em três etapas. Primeiramente será desenvolvida uma reflexão a respeito do ciberespaço e suas características. Tal caracterização tem por objetivo evidenciar as novas oportunidades de interação informacional criadas pelo advento da difusão da Internet. Em seguida é apresentado o procedimento de construção e análise de casos com a interface Panteon. Esta apresentação será suscinta, tendo em vista a discussão da mesma metodologia em artigos anteriores (LIMA, 2002; LIMA, KOEHLER \& SPIRO, 2004). Por fim, serão apresentadas sugestões, já testadas, de utilização da ferramenta em diferentes contextos do ensino de gestão.

\section{O Ciberespaço e a Produção de Sentido}

Como ter acesso às informações pertinentes ao desenvolvimento cognitivo em gestão e como ter a possibilidade de articulá-las e organizá-las? A dificuldade para tal articulação e organização é mais própria ainda quando se observa, especificamente, o ciberespaço, já que não se está mais na "frente" dos dispositivos comunicacionais, mas sim "dentro" deles. Não mais se observa, simplesmente, uma tela, há uma imersão em um 
volume que precisa da ação consciente do usuário; o usuário-operador, ativo, em contraposição ao espectador "passivo" (BETTETINI, 1996). Entretanto, esta interação requer do internauta algumas habilidades e ferramentas, sem as quais torna-se praticamente impossível achar alguma coisa na rede.

Ascott apud Lévy (1999) define este fenômeno, de forma metafórica, como o segundo dilúvio: o dilúvio de informações. Dentro desse contexto, Johnson (2001) afirma que "informação digital sem filtros é coisa que não existe" (JOHNSON, 2001. p. 33). Em um oceano de informações, para se localizar, o internauta precisa, cada vez mais, de instrumentos mediadores, como expresso no trecho:

Décadas atrás, Doug Engelbart e um punhado de outros visionários reconheceram que a explosão da informação poderia ser tanto libertadora quanto destrutiva - e sem uma metaforma para nos guiar por esse espaço-informação, correríamos o risco de nos perder no excesso de informação. (JOHNSON, 2001. p. 33) (grifos nossos)

Tem-se, assim, que esta metaforma sugerida por Johnson (2001) deve ser algo capaz de facilitar a atribuição de sentido às informações. A sugestão aqui é que o Panteon, na medida em que for alimentado por casos hipertextuais desenvolvidos por professores de gestão de todo o país, de acordo com a lógica de sua estrutura analítica (Figura 1) servirá como contexto das informações, facilitando a atribuição de sentido a estas. Assim, quanto maior a quantidade de informação disponível no Panteon, tanto maior será a sua utilidade como uma ferramenta para organização e recuperação de informações; essa é a sua utilidade como metaforma.

Um dos principais aspectos que caracterizam a complexidade do ciberespaço é a hipertextualidade. As formas tradicionais de se indexar documentos linearmente, como em uma biblioteca com livros de papel e estantes de madeira, não são capazes de dar conta das necessidades cognitivas atuais. No mundo físico, se um livro puder ser classificado em mais de uma categoria, será preciso mais de um exemplar para armazená-los nos diversos espaços correspondentes às categorias diferentes. No ciberespaço, com apenas um documento armazenado (que pode ser texto, som, imagem, vídeo, etc.), pode-se fazer tantas classificações quanto necessárias. Num exercício de imaginação inspirado na visão utópica da Biblioteca de Babel de Jorge Luis Borges (BORGES, 1941), é como se fossem colocadas diversas estantes se cruzando sendo que cada uma delas corresponderia a uma categoria diferente e, nos pontos de interseção, ficariam os documentos que compartilhassem de tais categorias. Ter-se-ia assim um emaranhado tão grande de estantes que seria improvável o deslocamento entre elas, por isso é aceitável que tal arrumação rizomática só seja possível dentro da lógica da rede, como no ciberespaço, que por sua vez deve desenvolver uma forma de indexação própria. Para Lévy (1993):

\begin{abstract}
Tecnicamente, um hipertexto é um conjunto de nós ligados por conexões. Os nós podem ser palavras, imagens, gráficos, seqüências sonoras, documentos complexos que podem eles mesmos ser hipertextos. Os itens de informação não são ligados linearmente (...) Navegar em um hipertexto significa portanto desenhar um percurso em uma rede que pode ser tão complicada quanto possível. Porque cada nó pode, por sua vez conter uma rede inteira. (Lévy, 1993. p. 33)
\end{abstract}

É preciso notar que o elemento "texto" em hipertextual está mais ligado à idéia de "tecido, trama de múltiplos fios", do que à composição de caracteres alfabéticos propriamente dita. Assim, o hipertexto envolve não apenas palavras, frases ou parágrafos escritos, mas também documentos áudio-visuais (LANDOW, 1992), o que eleva a sua complexidade e as suas possibilidades como suporte à aprendizagem. Hipertexto seria, então, a linguagem própria do ciberespaço. Lévy (1993) afirma que, ao navegar nesse oceano de informação através de uma tela, perde-se a referência espacial e sensório-motora, é como explorar um mapa através de pedaços minúsculos,em que cada pequeno pedaço traz consigo suas coordenadas.

Tem-se, nesse ponto, uma comparação inevitável entre esta característica hipertextual do ciberespaço e a característica hipertextual do conhecimento. Seria esta indexação proposta algo realmente factível? Haveria a possibilidade real de desenvolvimento de uma ferramenta que pudesse agir como uma luz divina de Petrarca, indicando ao leitor o que buscar e o que evitar? Não é isso que se sugere com o uso do Panteon; como se verá na sessão seguinte, esta ferramenta não tem a pretensão de indicar o caminho de cada analista/aprendiz, mas simplesmente de disponibilizar os elementos para a construção de uma teia cognitiva, um suporte à reflexão individual e colaborativa.

Morin (2004) apresenta sete saberes necessários à educação do futuro e, dentre eles, está o princípio do conhecimento pertinente. O autor faz uma crítica à disciplinarização e à especialização. Para ele, o conhecimento é cada vez mais multidisciplinar, transversal, multidimensional, transnacional, global e planetário. Assim, é necessário o desenvolvimento de uma 
educação que seja capaz de contextualizar as informações, como expresso em suas próprias palavras:

O conhecimento das informações ou dos dados isolados é insuficiente. É preciso situar as informações e os dados em seu contexto para que adquiram sentido. Para ter sentido, a palavra necessita do texto, que é o próprio contexto, e o texto necessita do contexto no qual se enuncia. (MORIN, 2004. p. 36)

Lévy (1993) corrobora afirmando que o contexto dá sentido à troca de informação, definindo o ato comunicacional. Para o autor, cada nova mensagem modifica o sentido integral da comunicação, como no xadrez, em que cada novo lance modifica o cenário do jogo.

Certamente, atribuir sentido às informações é uma grande dificuldade em meio a este oceano, pois o sentido de um documento está menos nele próprio do que nas pessoas que o consultam (AUTHIER, 1998). A diversidade de sentidos está em quem busca. No contexto da produção de sentido, o Panteon torna possível ao usuário recolher documentos e comentá-los, construindo uma trilha de interesse particular. Desta forma, o Panteon se torna cada vez mais associativo, capilar e denso com a experiência de cada usuário na medida em que este compartilha com os demais os resultados alcançados, gerando uma síntese dos resultados individuais. Ou seja, a proposta de adoção do Panteon está diretamente relacionada à aceitação de que ensino-aprendizagem é um processo de construção, numa abordagem multirreferencial e hipertextual e não de simples instrução, nem de repetição de modelos, apesar de se reconhecer aqui a importância de ambos.

\section{O Panteon e a Criação de Casos Hipertextuais}

O Sistema Panteon - presentemente disponível como uma ferramenta de uso livre ("freeware") em www.panteonweb.com.br nasceu da seguinte pergunta: se, conforme preconiza a médium theory (DEIBERT, 1997; MCLUHAN,1974), cada salto tecnológico corresponde, de fato, a um ganho potencial na capacidade de cognição humana, como as novas tecnologias de comunicação e informação podem contribuir para o processo de análise intersubjetiva de situações socialmente condicionadas? O projeto evoluiu para o conceito de acesso a um banco de dados via web que permitisse a qualquer indivíduo ou grupo de análise criar seus próprios elementos hipertextuais para diagnosticar problemas intra ou inter-organizacionais.

Através de sua estrutura analítica (Figura 1) o Panteon permite uma imersão do aprendiz em seu objeto de estudo, seja ele uma estrutura social ampla, uma organização ou mesmo um indivíduo.

O Panteon comporta o cadastramento de diferentes modelos de análise, situações-problema e estruturas organizacionais. Cada "caso" ou "episódio" pressupõe um trabalho de campo para levantamento de percepções dos atores organizacionais. Esses elementos alimentam a base de dados da interface, cujo "motor de busca" permite vasculhar as centenas ou milhares de percepções, facilitando ao analista "capturar" e comentar as falas que contenham elementos que venham a subsidiar o seu diagnóstico individual.

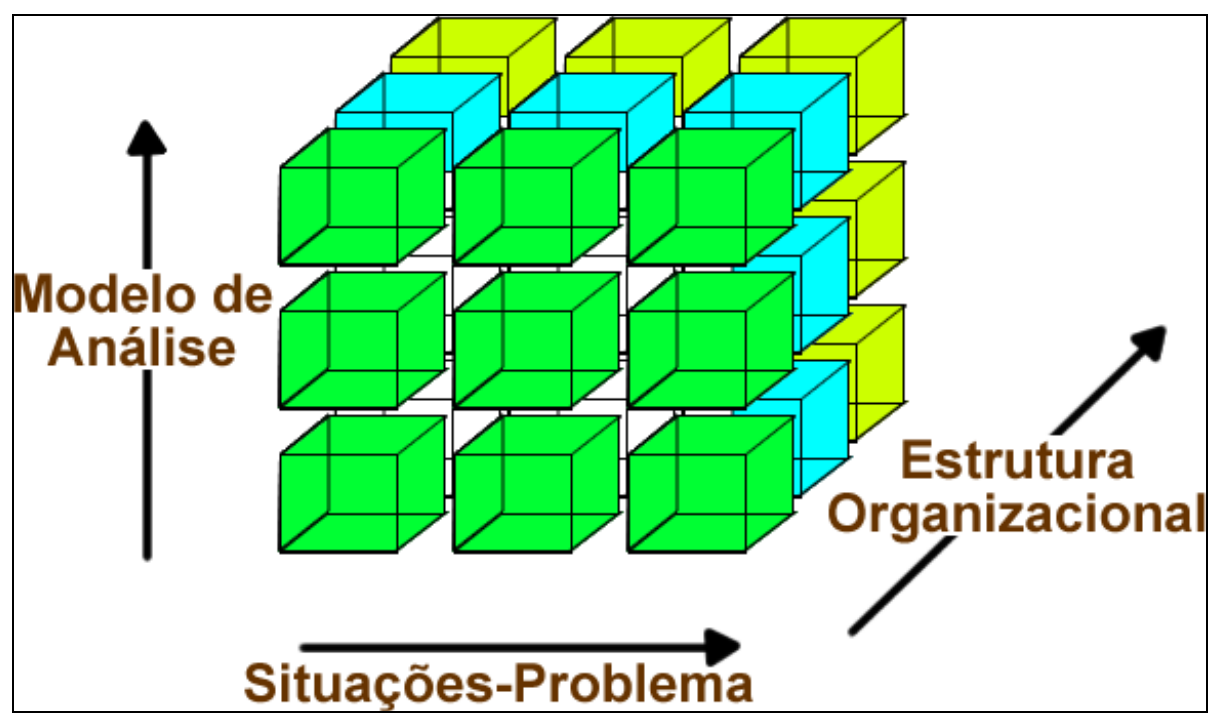

Figura 1. Estrutura Analítica do Panteon (Elaboração Própria) 
Os elementos que fazem parte da construção do caso para posterior análise são descritos em maior detalhe a seguir:

1. Modelo de análise: por "modelo" entende-se um determinado encadeamento heurístico de categorias de análise. É possível criar modelos próprios de análise ou adotar modelos pré-estabelecidos.

2. Aspectos genéricos e texto introdutório: aqui os pesquisadores/professores podem descrever o histórico do contexto de problema, o cenário competitivo ou os condicionantes sociais, a problemática atual e/ou o dilema aparente, os principais personagens, a cultura organizacional, aspectos informais das redes envolvidas e o que mais achar necessário para a contextualização introdutória. Podem também acrescentar anexos como relatórios, tabelas, fotografias, filmes, etc. Esses aspectos podem auxiliar o processo de análise dos aprendizes.

3. Estrutura organizacional: pesquisadores/professores devem definir como estão distribuídas as relações de poder ou os vínculos sociais entre os vários grupos envolvidos com o problema analisado. Em se tratando de uma análise organizacional, pode ser cadastrado aqui o organograma da instituição estudada.

4. Situações-problema: detalham os principais problemas, tais como "entrada de um novo concorrente" ou "perda de competitividade no segmento $Y$ " ou "aspectos-chave do atendimento ao turista da terceira-idade".

5. Personagens: é possível apresentar os diferentes atores que participaram do caso com opiniões, percepções, ou como é chamado no Panteon, pontos de vista. Ao criar cada personagem, os pesquisadores/professores devem lhes atribuir um nome, uma posição hierárquica, perfil psicológico e descrição relevante ao caso, mesmo que em algumas situações seja necessário preservar a identidade dos respondentes.

6. Percepções ou Pontos de Vista dos personagens: este é o ponto-chave para a construção de casos hipertextuais com o Panteon - a interface solicita dos pesquisadores/professores que, para cada personagem seja digitada pelo menos uma percepção conforme cada situação-problema na perspectiva de cada categoria de análise. Assim, por exemplo, o diretor de marketing (personagem) pode ter a seguinte percepção sobre uma ameaça (categoria de análise) associada à "entrada de um novo concorrente" (situação-problema): "se não reagirmos imediatamente com uma redução de preços e um aumento de qualidade, certamente teremos perda de fatias de mercado".

De fato, por oferecer um "motor de busca" textual com múltiplos critérios de filtragem, a interface hipertextual permite que o usuário se fixe em uma determinada categoria de análise do modelo (como "potencialidades", "fragilidades", "oportunidades" e "ameaças", no caso de uso do modelo PFOA) enquanto explora as várias situações-problema em determinados setores da estrutura organizacional. Pode, alternativamente, manter fixa a situação problema (como "perda de vendas" ou "queda de qualidade" ou "conflitos de poder") e olhá-la de acordo com as múltiplas categorias do modelo e em vários níveis da estrutura. Pode, ainda, deter-se num setor específico da estrutura interna ou externa ("alta administração" ou "terceirizados" ou "fornecedores") e observá-la com base nas múltiplas categorias do modelo e de acordo com as várias situações problemas apresentadas. Pode, por fim, fazer variar todos esses elementos numa busca randômica por frases e percepções baseados em palavras-chave desconexas como "dinheiro", "poder" ou "conflitos".

Para que o cadastramento do caso seja possível, o pesquisador/professor deve ter definido anteriormente a base da estratégia metodológica que será utilizada, pois o cadastro dos pontos de vista ou percepções do personagem só pode ser realizado após serem definidos o modelo de análise, a estrutura organizacional e as situaçõesproblema.

Conforme os princípios propostos pela Teoria da Flexibilidade Cognitiva (SPIRO, 1992; JONASSEN et al., 1997; SPIRO e JEHNG, 1990), quanto mais pontos de vista sobre o mesmo aspecto de um domínio de conhecimento pouco estruturado, maior a capacidade de representar a complexidade inerente. Num estudo de caso minimamente complexo, se doze personagens emitem percepções sobre quatro situações-problema de acordo com cada uma das cinco categorias de um modelo de análise qualquer, obtém-se - no máximo - um total de 240 parágrafos de percepções. Como nem todos os personagens terão necessariamente uma opinião sobre cada situação com base em todas as categorias de análise, este número pode ser significativamente reduzido, mas ainda assim restarão mais de uma centena de opiniões a serem analisadas. É precisamente na navegação não-linear desta miríade de percepções que reside a complexidade 
de representação dos contextos em que os problemas organizacionais ocorrem; não baseados apenas em fatos objetivos, mas na subjetividade inerente aos múltiplos pontos de vista, suas contradições, complementaridades, redundâncias e ambigüidades.

Os exemplos a seguir tornarão mais claro como as características hipertextuais do Panteon podem apoiar os raciocínios crítico e criativo de estudantes de gestão em três diferentes contextos. Para compreender a interface em maior detalhe, sugerese visitar o site www.panteonweb.com.br e clicar na opção "o que é?".

\section{O Panteon no Ensino de Gestão}

Nos últimos dois anos, nove experiências com o sistema Panteon foram desenvolvidas. Essas experiências foram feitas com turmas de gestão em nível de graduação, de especialização e de mestrado/doutorado. Pode-se dividir as experiências em três formas distintas de acordo com o métodos de aplicação: a) análise de casos previamente cadastrados; b) desenvolvimento de novos casos para sua subseqüente e análise; e c) o uso de casos hipertextuais para a análise qualitativa em jogos de empresa. Em cada um desses métodos foram observados elementos como a receptividade dos alunos para com a ferramenta, suas vantagens e desvantagens em relação a métodos tradicionais de análise organizacional.

A análise de casos previamente cadastrados é aquela que apresenta maior proximidade com o tradicional "Método Harvard" e o maior ganho de escala com o uso da ferramenta, já que um caso desenvolvido pode ser trabalhado em inúmeras turmas diferentes. Este método foi testado em uma turma de graduação em administração (21 alunos) e uma de turismo (18 alunos) em análises gerais (que envolviam uma situação social como um todo) e outra turma de administração (12 alunos), onde se pretendia desenvolver análise específica (análise da estrutura organizacional). Totalizam-se, desta forma, 51 alunos que desenvolveram atividades com o Panteon nesta modalidade. Os casos utilizados foram o "Condor" e o "Turismo para a Terceira Idade" (desenvolvido em outra experiência relatada adiante). Neste método específico, os alunos relataram que os principais aspectos desenvolvidos pela ferramenta são o trabalho em grupo, a investigação e a resolução de problemas. A turma que desenvolveu a análise específica foi a que demonstrou maior interesse com a atividade. Suspeita-se que o motivo esteja relacionado à complexidade dos casos, já que a turma que analisou o caso Condor (que contém mais de 300 percepções a serem analisadas) comentou a respeito da saturação e da monotonia num determinado ponto do desenvolvimento da atividade. Apesar da ferramenta não propor uma completude de análise individual (até porque isso se daria através das sínteses grupais), o costume de leituras lineares sugere aos analistas/aprendizes que uma atividade só está completa ao se passar por todas as etapas de leitura (PALÁCIOS, on-line). Assim, este trabalho supõe que casos grandes devam ser trabalhados em etapas bem delimitadas pelo professor, de acordo com os as habilidades e conteúdos esperados para a disciplina.

A modalidade de desenvolvimento de novo caso para subseqüente análise é aquele que demanda maior tempo para a atividade e o que obtém os melhores resultados em termos de disposição dos alunos à participação. Esta abordagem foi aplicada em uma turma de graduação em Administração (14 alunos) e noutra de especialização em Gestão (27 alunos). Na primeira, toda a turma foi responsável pelo desenvolvimento do caso "Turismo para a Terceira Idade", cujos resultados foram publicados recentemente (MOTTA e LIMA, 2007). Já na segunda, cada aluno deveria desenvolver seu próprio caso. Totalizam-se, desta forma, 41 alunos que desenvolveram atividades com o Panteon nesta categoria. A turma que desenvolveu um trabalho conjunto foi a que, dentre todas as experiências, conseguiu um melhor resultado geral, já que os alunos relataram o gerenciamento de conflitos, a produção de conhecimento e a aplicação prática numa situação real do ambiente de negócios como os principais aspectos desenvolvidos pela atividade. $\mathrm{Na}$ turma que desenvolveu casos individuais foi negligenciada a capacidade da ferramenta de construção de um trabalho em grupo, mas estimulou, segundo relato dos próprios alunos, uma maturidade para tratar problemas organizacionais reais. Entretanto é importante deixar anotado que dos 27 alunos deste subgrupo, 9 não concluíram a atividade como um todo. Desses muitos alegaram indisponibilidade de tempo.

O terceiro método experimentado foi 0 de análise qualitativa em jogos de empresa. Goldschmidt (1977) afirma que "o jogo de empresas se aproxima de um estudo de caso, onde adicionamos duas variáveis: uma é o feedback - o retorno das informações; a outra é a dimensão temporal que, geralmente, os casos não têm" (GOLDSCHMIDT, 1977, p. 43). E complementa indicando que uma grande crítica à utilização dos jogos de empresas é o reducionismo da operacionalização de variáveis; "é a de que ele 
obedece a uma orientação basicamente quantitativa" (GOLDSCHMIDT, 1977, p. 45). Desta forma, foi desenvolvida uma experiência combinando a utilização de duas ferramentas (um simulador empresarial e o sistema Panteon), que buscava oferecer uma orientação mais qualitativa à técnica de jogos de empresas. Num primeiro momento, na ocasião da aplicação da atividade com a turma de mestrado/doutorado em Administração (13 alunos), foram extraídas as principais informações do simulador e alimentadas no Panteon como um caso (como se fossem os jornais dos jogos de empresas, entretanto dispostos hipertextualmente). A cada rodada, após as decisões do grupo, era gerado um novo caso no Panteon com os resultados obtidos na simulação. A grande dificuldade reside na necessidade de alimentar um novo caso a cada rodada. Assim, foi experimentada uma alternativa simplificada com outras três turmas: uma de Administração (55 alunos), uma de Ciências Contábeis (21 alunos) e uma de Secretariado Executivo(33 alunos). Totalizam-se, desta forma, 122 alunos que desenvolveram atividades com o Panteon, na abordagem de análise qualitativa em jogos de empresa. A turma de mestrado/doutorado, provavelmente por conta da finalidade mais acadêmica e menos profissionalizante do curso, apresentou menor interesse no desenvolvimento da atividade e maior no funcionamento do Panteon para análise de dados qualitativos. Os alunos de graduação relataram 0 aprofundamento das discussões relativas às tomadas de decisão como uma das maiores virtudes do uso combinado do Panteon e de Jogos de Empresas. Cada decisão precisa ser discutida por todos os envolvidos, que já analisaram sob diversos aspectos. Isso faz com que as informações estejam mais articuladas e a probabilidade de decisões incoerentes seja significativamente menor.

Todos os relatos apresentados por participantes das experiências demonstram o grande potencial da ferramenta em sua utilização em sala de aula. Aspectos, como os já discutidos, relativos à necessidade do processo de ensino-aprendizagem em gestão (trabalho em equipe, complexidade, tomada de decisões, competência informacional e multirreferencialidade) parecem ser trabalhados pelo Panteon. É possível solicitar a construção de uma síntese coletiva, estimulando o trabalho em equipe; o sistema leva a uma análise heurística, considerando toda a complexidade da realidade organizacional; o analista precisa tomar decisões ao sugerir um plano de ação e, para isso, conta com uma estrutura de argumentos que o permitem o desenvolvimento de uma análise sistemática e racional; a oferta de múltiplas fontes de dados (som, texto e imagem) e a estrutura analítica do Panteon permitem a contextualização e atribuição de sentido às informações, desenvolvendo a competência informacional; e, a construção de uma trilha de interesse particular, permite a utilização das diversas referências individuais dos analistas e, ainda, a negociação destas para o desenvolvimento de uma síntese coletiva entre os diversos analistas.

\section{Considerações Finais}

A Internet vem sendo sistematicamente subutilizada enquanto suporte à cognição humana. Assim como a escrita manual ajudou no desenvolvimento tecnológico das sociedades primitivas, e assim como a imprensa de Gutenberg permitiu a colaboração científica que influenciou a Era do Iluminismo e a Revolução Industrial, a capacidade de facilitar o compartilhamento de textos, sons e imagens mediadas por bancos de dados confere à Internet um potencial ainda inexplorado de tornar-se um importante instrumento de apoio à cognição, seja para fins de resolução de problemas organizacionais, seja para exercitar, em estudantes, as faculdades do pensamento crítico e analítico. Este potencial, associado ao esforço colaborativo de professores e pesquisadores em gestão, resultará na emergência de uma base de dados que poderá ser trabalhada em todos os cantos do país e ainda permitirá a interlocução entre os professores, pesquisadores e aprendizes em gestão, favorecendo o desenvolvimento colaborativo de produção de conhecimento na área.

Da fundamentação teórica do Panteon, segundo Lima (2003b), pode-se destacar quatro aspectos básicos do sistema que estão intimamente alinhados às atuais necessidades educacionais em gestão. São eles: a necessidade de verificação de diversos tipos de fontes (texto, som e imagem) no processo de tomada de decisão, a importância dada à complexidade dos pontos de vista dos personagens envolvidos na situação estudada, a flexibilidade na estruturação das informações e a construção de uma síntese coletiva, fruto de um trabalho em equipe.

A forma como os dados são organizados no Panteon tem como objetivo facilitar o processo de análise. Existem diversas possibilidades de criação de categorias e variáveis que servirão como critérios de seleção no momento da análise. A maior ou menor exploração dessas possibilidades de divisão e arrumação das informações dependerá dos estudos que serão realizados e dos seus objetivos. O importante é que o sistema 
demonstrou-se bastante flexível e pode adaptar-se a diferentes tipos de abordagens didáticas. $O$ Panteon define uma estrutura básica onde se dá o armazenamento e a análise das informações. As características mais específicas podem ser definidas de forma particular para cada estudo, havendo assim a possibilidade de adaptação do sistema para diversas situações.

O Panteon permite uma grande integração com os objetivos de uma análise qualitativa de casos por não se propor a reduzir os fenômenos à operacionalização de variáveis (como fazem, por exemplo, os jogos de empresas). A ferramenta permite lidar com toda a complexidade qualitativa de um ambiente estudado, evitando a supersimplificação típica de abordagens tradicionais. Apesar de complexa, a interação com tal ambiente de análise é facilitada pelas funcionalidades hipertextuais da interface, que auxiliam no processo de síntese através da sistematização de informações relevantes em categorias determinadas pelo pesquisador. A organização dos fragmentos do caso, em categorias, permite uma análise focada em um determinado modelo, diagnosticando as partes separadamente para uma posterior síntese que levará ao todo.

Por ser baseada na web, a ferramenta permite ainda uma análise conjunta não-presencial e assíncrona; assim, é possível reunir um grupo de aprendizes sem a necessidade de que estejam todos num mesmo espaço, nem que trabalhem ao mesmo tempo. Desta forma, torna-se possível e bastante pertinente sua utilização nos cursos realizados à distância, tão comuns atualmente.

Além das três formas de utilização aqui apresentadas, a ferramenta pode ser também utilizada simplesmente como um apoio ao tratamento de percepções ou falas de atores organizacionais para análise qualitativa individual e colaborativa. Detalhes de como isso pode ser feito foram publicados recentemente (MOTTA, LIMA e WANDERLEY, 2007).

Um último aspecto potencializador da ferramenta é o seu caráter aberto e seu acesso gratuito. Qualquer estudante ou pesquisador pode utilizar a interface sem a necessidade de pagamento de licenças. Esse caráter gratuito tornou-se possível graças ao sistemático aporte de recursos públicos para o desenvolvimento da interface. Após ter sido premiada com recursos da Fundação de Amparo à Pesquisa do Estado da Bahia e incubada durante dois anos, a ferramenta ganhou uma versão bem mais avançada do que o protótipo utilizado na tese de doutorado que lhe deu origem em 2003. Em 2007, o Sistema Panteon integrou uma proposta liderada pelo Instituto Anísio Teixeira para difusão de instrumentos didáticos multi-media, submetida aos Ministérios da Educação e da Ciência e Tecnologia. Tal proposta, por sua vez, foi contemplada com recursos da ordem de $\mathrm{R} \$ 1,4$ milhão, o que permitirá continuar ainda por muitos anos a investigação do potencial de suporte cognitivo da interface a fim de adaptá-la a outras áreas do conhecimento.

Conclui-se, a partir do êxito das três abordagens de uso do Panteon, que essa plataforma pode vir de fato a se tornar uma espécie de "biblioteca de hipertextos para análise organizacional" em todo o País. Para tanto, faz-se necessário articular-se uma rede de pesquisadores interessados em propor conteúdo para o sistema. Isso pressupõe o apoio de uma associação nacional envolvida com inovações no ensino de gestão, como a Associação Nacional de Programas de Pós-Graduação em Administração (ANPAD) ou a associação congênere para a graduação, ANGRAD.

Mais do que tempo e recursos financeiros, uma tal proposta implica uma abertura de espírito para as novas possibilidades de suporte cognitivo oferecidas pelo ciberespaço para os processos de análise organizacional. Este artigo procurou demonstrar a partir de três contextos didáticos distintos como os elementos básicos da revolução cognitiva em curso já estão à nossa disposição para testar, adaptar e inovar nas práticas de ensino-aprendizagem de gestão.

\section{Referências}

AUTHIER, M. Pays de connaissances. Paris : Rocher, 1998.

BETTETINI, Gianfranco. Semiótica, computação gráfica e textualidade. In: PARENTE, André. Imagem-máquina: a era das tecnologias do virtual. Rio de Janeiro: Ed. 34, 1996.

BORGES, Jorge Luis. Biblioteca de Babel. InfoHome. 1941. Disponível em:

http://www.ofaj.com.br/textos.html. Acesso 25 de novembro de 2004.

DEIBERT, Ronald J. Parchment, printing and hypermedia. Nova York: Columbia University Press, 1997.

GOLDSCHMIDT, P. C. Simulação e jogo de empresas. Revista de Administração de Empresas. v.17, n.3, Rio de Janeiro: FGV, maio/jun.1977, pp.43-46.

Isaac, J. R. Identifying educational core competencies for the information age. In: Taylor, 
Harriet e Horgenbirk, Pieter (Org.). Information and communication technologies in education: The school of the future. Boston: Kluwer Academic Publisher: 2001.

JOHNSON, Steven. Cultura da interface: como o computador transforma nossa maneira de criar e comunicar.Rio de Janeiro: Jorge Zahar Editor, 2001.

JONASSEN, David et al. Cognitive flexibility hypertexts on the web: engaging learners in meaning making. In: Khan, Badrul H. (Org.). Webbased Instruction. Englewood Cliffs: Educational Technology Publishing, 1997.

JONES, Manley Howe. Tomada de decisões pelo executivo. São Paulo: Atlas, 1973.

LANDOW, George. Hypertext: the convergence of contemporary critical theory and technology. Baltimore: John Hopkins Press, 1992

LÉVY, Pierre. As tecnologias da inteligência. Rio de Janeiro: Ed. 34, 1993.

1999.

Cibercultura. Rio de Janeiro: Ed. 34,

LIMA, Marcos. Estudos de Casos Hipertextuais: Rumo a uma Inovação no Método Harvard de Ensino de Gestão. In: ENCONTRO ANUAL DA ASSOCIAÇÃO NACIONAL DOS PROGRAMASDE PÓS-GRADUAÇÃO EM ADMINISTRAÇÃO - Anais do XXVI ENANPAD. Salvador, Setembro de 2002.

Estudos de casos hipertextuais: rumo a uma inovação no método Harvard de ensino de gestão. Revista de Administração

Contemporânea, Curitiba, v. 7. n. 3, jul-set., $2003 a$.

Potencial de suporte cognitivo das tecnologias interativas de comunicação: desenvolvimento de uma interface hipertextual dinâmica para análise organizacional baseada em estudos de casos. Tese de doutorado - Programa de Pós-Graduação em Comunicação e Cultura Contemporâneas, Universidade Federal da Bahia, Salvador, agosto de 2003b.

Interfaces hipertextuais e o potencial de aprendizagem mediada por novas tecnologias de comunicação. Comunicarte Revista de

Comunicação e Arte, Aveiro, Portugal. v. 1, n. 1, p. 41-46, 2001.

LIMA, Marcos; KOEHLER, Matthew; SPIRO, Rand. cognitive flexibility hypertexts and the development of creative and critical thinking in business education: The Panteon project. In: XXVIII ENCONTRO DA ASSOCIAÇÃO NACIONAL DE PÓS-GRADUAÇÃO EM ADMINISTRAÇÃO, 2004, Curitiba. Anais do XXVIII ENANPAD. 2004.
MCLUHAN, Marshall. Os meios de comunicação como extensão do homem. São Paulo: Cultrix, 1974.

MORIN, Edgar. Os sete saberes necessários à educação do futuro. São Paulo: Cortez; Brasília, DF: UNESCO, 2004.

MOTTA, Gustavo; LIMA, Marcos Cerqueira. Indicações para a gestão da qualidade em serviços turísticos para consumidores da terceira idade: uma análise qualitativa com a interface Panteon.

Caderno Virtual de Turismo, Rio de Janeiro, v. 07, n. 01, p. 52-62, 2007.

MOTTA, G.; LIMA, M.C.; WANDRELEY, Y.B. O uso do sistema panteon para pesquisa qualitativa em análise organizacional. Diálogos Possíveis, Salvador, ano 6, n. 02, 2007.

OKADA, Alexandra ; ALMEIDA, Fernando. Navegar sem mapa? In: LEÃO Lúcia. (org.) Derivas: cartografias do ciberespaço. São Paulo: Senac, 2004.

PALÁCIOS, Marcos. Hipertexto, Fechamento e o uso do conceito da não-linearidade discursiva. Disponível em:

$<$ http://www.facom.ufba.br/ciberpesquisa/palacios/h ipertexto.html> Acesso em: 11/04/2008.

ROSAS, A. R. ; SAUAIA, A. C. A. Jogos de empresas na educação superior no Brasil: perspectivas para 2010. In: XXX EnANPAD Encontro da Associação Nacional de Programas de Pós-Graduação em Administração, 2006, Salvador, BA. Anais do XXX EnANPAD, 2006. v. 1. p. 1-15.

SPIRO, Rand J. Knowledge representation, content specification, and the development of skill in situation specific knowledge assembly: some constructivist issues as they relate to cognitive flexibility theory and hypertext. In: Jonassen, David e Mandl, H. (Org.). Constructivism and the technology of instruction. Hillsdale: LEA, 1992.

SPIRO, Rand J. e JEHNG, J. C. Cognitive flexibility and hypertext: theory and tecnology for nonlinear and multidimensional traversal of complex subject matter. In: Nix, Don e Spiro, Rand J. (Org.).

Cognition, education, and multimedia: exploring ideas in high technology. Hillsdale, N.J.: L. Erlbaum, 1990.

VICENTE, Paulo. Jogos de empresas. São Paulo: MAKRON Books, 2001. 